\title{
Impact of Management Practices on Prevalence of Soybean Sclerotinia Stem Rot in the North-Central United States and on Farmers' Decisions Under Uncertainty
}

\author{
A. L. Mila, Department of Plant Pathology, A. L. Carriquiry, Department of Statistics, J. Zhao, Department of \\ Economics, and X. B. Yang, Department of Plant Pathology, Iowa State University, Ames 50011
}

\begin{abstract}
Mila, A. L., Carriquiry, A. L., Zhao, J., and Yang, X. B. 2003. Impact of management practices on prevalence of soybean Sclerotinia stem rot in the north-central United States and on farmers' decisions under uncertainty. Plant Dis. 87:1048-1058.

Regional prevalence of soybean Sclerotinia stem rot (SSR), caused by Sclerotinia sclerotiorum, was modeled using management practices (tillage, herbicide, manure and fertilizer application, and seed treatment with fungicide) and summer weather variables (mean monthly air temperature and precipitation for the months of June, July, August, and September) as inputs. Logistic regression analysis was used to estimate the probability of stem rot prevalence with disease data from four states in the north-central region of the United States (Illinois, Iowa, Minnesota, and Ohio). Goodness-of-fit criteria indicated that the resulting model explained well the observed frequency of occurrence. The relationship of management practices and weather variables with soybean yield was examined using multiple linear regression $\left(R^{2}=0.27\right)$. Variables significant to SSR prevalence, including average air temperature during July and August, precipitation during July, tillage, seed treatment, liquid manure, fertilizer, and herbicide applications, were also associated with high attainable yield. The results suggested that SSR occurrence in the north-central region of the United States was associated with environments of high potential yield. Farmers' decisions about SSR management, when the effect of management practices on disease prevalence and expected attainable yield was taken into account, were examined. Bayesian decision procedures were used to combine information from our model (prediction) with farmers' subjective estimation of SSR incidence (personal estimate, based on farmers' previous experience with SSR incidence). MAXIMIN and MAXIMAX criteria were used to incorporate farmers' site-specific past experience with SSR incidence, and optimum actions were derived using the criterion of profit maximization. Our results suggest that management practices should be applied to increase attainable yield despite their association with high disease risk.
\end{abstract}

Additional keywords: Bayesian behavior, white mold

In recent years, Sclerotinia stem rot of soybean (SSR), caused by Sclerotinia sclerotiorum (Lib.) de Bary, has emerged as a leading cause of soybean yield losses in the north-central soybean production region of the United States. Before the 1990s, the disease is known to have caused only localized epidemics in Michigan, Minnesota, and Wisconsin (18), where soybeans of maturity groups 0 to I are grown. In the same region, SSR was ranked twelfth as a cause of yield losses in 1990 (11) and second in 1994 (55). During the 1996 growing season, the disease was found in epidemic proportions in Iowa (53), much more severe than in 1992 and 1994 (56).

Corresponding author: A. L. Mila

E-mail: mmila@uckac.edu

Current address of A. L. Mila: Department of Plant Pathology, University of California-Davis, Kearney Agricultural Center, Parlier, CA 93648.

Accepted for publication 3 April 2003.

Publication no. D-2003-0626-01R

(C) 2003 The American Phytopathological Society
Management practices intended to increase soybean yield (such as narrow row spacing, increased plant populations, early planting dates, and high soil fertility), reduced tillage, or rotation with susceptible crops are factors that increase the soil inoculum density and may also contribute to the increased SSR occurrence in the northcentral region of the United States $(12,19,29,34,42)$. Finally, above-normal precipitation and low temperatures occurring during the critical infection period of flowering also favor SSR development (53).

Deep plowing has been recommended for control of white mold (51). In a study (42) on dry edible beans, it was shown that a 3-year rotation did not reduce sclerotium populations significantly, suggesting that attempts to manipulate sclerotial populations may have limited effect on either soilborne or airborne inoculum density. No-tillage significantly reduces SSR occurrence (29,53). Fewer apothecia have been found in no-tillage $(16,29)$. Fertilizers have been found to have contradictory effects on S. sclerotiorum: in one study they did not affect sclerotium germination
(42), while in another (12) application of fertilizers increased significantly the number of produced apothecia. Manure applications were positively correlated to SSR incidence (37), and increased carpogenic germination has been observed in soils with high organic matter content (13).

Planting in wide rather than narrow row widths (46) or at low plant populations (22) has been suggested as a successful management practice for SSR control since it reduces canopy density. Dense canopy creates favorable humidity and temperature conditions for SSR development within the canopy $(5,6)$. Treatment of sunflower seeds with benomyl, iprodione, or vinclozolin eliminated seedborne $S$. sclerotiorum and increased the number of surviving seedlings (23). The fungus uses the seed as a nutrient base to produce sclerotia in soil and thus establishes itself in new fields $(1,49)$. For that reason, seeds infected with mycelia may serve as a means of $S$. sclerotiorum dissemination over long distances (1).

Increase in Sclerotinia stem rot incidence in the north-central region of the United States is associated with yield losses and is of concern for two reasons: the scarcity of resistant cultivars in the maturity groups appropriate for the region, and the cost of fungicides for control of Sclerotinia stem rot $(20,29,35)$. Sclerotinia stem rot can be controlled successfully by fungicides in susceptible crops such as dry bean and canola (45), but chemical control of SSR in soybean has not proven economically feasible $(17,29)$. Complete resistance to SSR has not been reported $(17,19,29)$, and only recently have cultivars with some resistance to SSR been planted in the region. As a result, current strategies for controlling SSR in soybean emphasize the use of management practices that reduce canopy density (45).

Farmers are interested in profit or net return from farming (48). Most farmers do not try to maximize yield while ignoring costs; instead, expenses involved in crop production and disease management are also included, so the net return from crop production can be calculated (48). If net return is the sole criterion used by a producer to choose between two or more alternatives, then the one with the highest expected monetary value (EMV) would be the one chosen $(2,48)$. Farmers, however, may have different preferences for certain practices because of the individual's cur- 
rent situation, the EMV for a given practice, and the perceived probabilities for a situation (e.g., SSR incidence in a field). Economists use the concept of utility to encapsulate such information, and if individuals' utilities are known, one can attempt to optimize the expected utility instead of EMV $(2,48)$.

Several studies on the risks and profitability of different soil-conserving tillage practices have been conducted, but the results are inconsistent. Some studies suggest that conservation tillage is the most profitable system although the most uncertain about expected yield (28), while others show that average net returns per acre are higher for conventional tillage systems than for other tillage systems (14). Narrow row spacing is mainly for weed control, but it is also associated with high plant populations and high potential yields (26,38). Seed treatments with Benlate, Captan, Vitavax, and Topsin have been reported to contribute to higher germination and yield than nontreated seeds (43). In another study, seed treatments were associated with reduced cultivar susceptibility to seedling diseases due to protection against soilborne pathogens and improved seed quality (32).

Studies by Savary et al. $(40,41)$ have quantified the effects of management practices on yield and disease incidence on a large geographic scale. These studies developed protocols for characterizing patterns of rice cropping practices and showed the potential for developing pest management strategies that can be adapted throughout tropical and subtropical Asia, rather than being site-specific. Sclerotinia stem rot in the north-central U.S. production system provides a model system for this type of study because of the voluminous data collected on the disease in this region (52-54).

The objectives of our study were: (i) to quantify the effect of input production variables on SSR prevalence; (ii) to investigate the relationship between yield and production variables that affect SSR occurrence; and (iii) to examine the effect of soybean farmers' production decisions on SSR incidence using decision theory under uncertainty.

\section{MATERIALS AND METHODS}

Data collection. In 1995 and 1996, soil and soybean stem samples were collected sometime between the last week of September and the first week of November from 1,155 fields in Illinois, Iowa, Minnesota, and Ohio by the National Agricultural Statistical Service (NASS). In total, 352 fields in Illinois, 398 in Iowa, 220 in Minnesota, and 185 in Ohio were sampled. The soybean fields sampled in 1996 were different from those sampled in 1995 because of the corn-soybean rotation schemes used in the U.S. Corn Belt. Details on the method used for field selection have been reported elsewhere (54). We describe data collected as follows:

(i) SSR incidence data. Twenty stems were collected from each sampled field in a zigzag pattern. Stems were externally observed for presence or absence of lesions. The stems were also longitudinally split and checked for presence or absence of sclerotia in the pith. For stems with signs and symptoms that could not be readily identified, isolation was made on acidified potato dextrose agar for further verification. SSR was found in 58 of the 1,155 sampled fields ( 2 in Illinois, 2 in Ohio, 35 in Iowa, and the rest in Minnesota). The disease incidence was lower than $16 \%$ in $84.5 \%$ of the cases where SSR was found; only in one case was the disease incidence very high $(80 \%)$. In this study, the term "prevalence" is used to describe the percentage of fields in which the disease was found, and the term "incidence" is used to describe the percentage of infected soybean plants sampled in a field.

(ii) Soybean yield data. In each field, NASS had established and maintained two yield-assessment plots. Yield data used in this study are the average yield of the two assessment plots.

(iii) Soil texture data. Soil was collected from each field, and soil texture was determined by methods previously described (54).

(iv) Management practices data. NASS enumerators interviewed farmers about management practices (irrigation, tillage, herbicide, manure and fertilizer application, and seed treatment with fungicide) that had been used in the sampled fields.

(v) Weather data. Mean monthly air temperature and precipitation for the months of June, July, August, and September were obtained from the National Oceanic and Atmospheric Administration (NOAA) through the National Climatic Data Center (NCDC) in Asheville, NC. For each sampled field, mean monthly temperature and precipitation were obtained from the nearest weather station. In $82 \%$ of the cases, the sampled fields were located less than $20 \mathrm{~km}$ from the nearest weather station. Only in 18 cases in Illinois, 8 in Iowa, 7 in Minnesota, and 11 in Ohio was the distance between field and weather station greater than $20 \mathrm{~km}$. SSR was not found in any of the fields located a distance greater than $20 \mathrm{~km}$ from the nearest weather station.

Correlation between variables. (i) Continuous variables were tested for possible correlation (using the CORR procedure in SAS; Statistical Analysis Systems: SAS Institute, Inc., Cary, NC). (ii) Twoway contingency tables were used to examine any possible associations between the categorical variables used in the models. The null hypothesis of independence between any two categorical variables was tested using a chi-square test. (iii) To check the possibility of association between con- tinuous and categorical variables, the null hypothesis of no difference between the means of the continuous variable within each category of categorical variables was tested using a $t$ test at $95 \%$ level of significance. In this case, the values of each categorical variable (two for all categorical variables, except the case of manure application where the values are three) are equivalent to different treatments used in an experimental design. Collinearity among predictors is important and should be investigated before any quantification takes place, since it may affect the efficiency of estimated parameters.

SSR prevalence model. Logistic regression was used to identify factors significantly associated with regional prevalence of SSR. If the dependent variable $Y i$ is the absence $(Y i=0)$ or presence $(Y i=1)$ of the disease in the $i$ th field, the probability of disease presence is modeled as:

$$
\begin{gathered}
P(Y i=1)=\exp \left(a+\Sigma b_{j} X_{j}\right) / \\
{\left[1+\exp \left(a+\Sigma b_{j} X_{j}\right)\right]}
\end{gathered}
$$

where $i=1, \ldots, n$ and $j=1, \ldots, p$. Here, $a$ and $b_{1}, \ldots, b_{p}$ are parameters to be estimated, and $X_{j}$ 's are covariates or predictors. They are similar to the intercept and regression coefficients in an ordinary multiple regression model. However, their interpretations are somewhat different from these in logistic regression (24). The LOGISTIC procedure in SAS was used to estimate parameters in equation 1 . The numbers of concordant and disconcordant pairs and correlation indices, such as Somers' D, Gamma, and c (equivalent to $R^{2}$ for linear regression analysis) were used to select the best fitted model. A pair is called concordant when the observation with the larger ordered value of the response has a lower predicted event probability than the observation with the smaller ordered value of the response. A pair is called discordant when the observation with the larger ordered value of the response has a higher predicted event probability than the observation with the smaller ordered value of the response. A model fits the data well when the proportion of concordant pairs is high and the proportion of disconcordant pairs is low. The correlation indices are computed from the numbers of concordant and discordant pairs of observations. A model with higher values for these indices has better fitness than a model with lower values for these indices.

Soybean yield quantification. Linear multiple regression analysis was used to quantify the effects of weather variables and management practices on yield. First, separate stepwise procedures were used for assessing the relationships between the independent and dependent variables. Then a multiple regression model was selected using backward elimination procedure. Starting from a saturated (or full) model, we sequentially dropped covariates or predictors not significantly associated with the 
response variable. Criteria used to evaluate the model were the graphical appraisal of randomness and normality of the residuals, coefficient of determination $\left(R^{2}\right)$, and $F$ value (36). In this study, regression analysis was used to describe the relationship between the variables that contribute to SSR prevalence and yield rather than to develop a model for yield prediction.

Input variables. Variables are listed in Table 1. Average air temperature during July and August, precipitation from June to August, no-tillage, minimum tillage, and conventional tillage, percentage of soil sand, clay, and silt, seed treatment, herbicide, manure, and fertilizer applications were used as input variables for the disease model. Average air temperature of July and August and air temperature of September, precipitation during June, July, August, and September, tillage practices, percentage of sand, clay, and silt in the soil, seed treatment, herbicide, manure, and fertilizer application were used as input variables for the description of yield variation.

Irrigation was used in eight fields (three in Illinois and five in Iowa) in 1995 and in three fields (one in Illinois, one in Iowa, and one in Minnesota) in 1996. SSR was not found in any of the irrigated fields. Because of the very small number of irrigated fields (11 of 1,155 sampled fields), which generated technical difficulties in the analysis, irrigation was not included in the final analysis. Tillage systems were classified into three categories according to the amount of surface residue (3). Conser- vation tillage systems maintain greater than $30 \%$ surface residue after planting. Tillage practices that maintain 15 to $30 \%$ surface residues are categorized as minimum-till, whereas those that maintain less than $15 \%$ surface residue are classified as conventional till. There were 331 fields in notillage, 409 in minimum till, and 415 in conventional tillage in 1995 and 1996. We considered two types of manure application: dry broadcast with or without incorporation and liquid broadcast with or without incorporation. Sources of manure were beef, hogs, pigs, and dairy. Fertilization included $\mathrm{K}_{2} \mathrm{O}$ application $(100 \%$ of cases where fertilizer was applied), $\mathrm{P}_{2} \mathrm{O}_{5}$ and $\mathrm{N}$ application (72 and $12 \%$, respectively, of the cases where fertilizer was applied). Fungicides used in seed treatments were not available and could have been applied by seed companies or interviewed farmers.

Management practices were used in the prevalence and yield models as indicator variables. Also, an indicator variable was used to capture any regional difference on SSR prevalence and yield among the states used in the analysis. Full explanation of the way management practices and regional (state) effects were incorporated in the analysis is given in Table 1 . An indicator variable is used to quantify qualitative differences among groups, such as in our case regional differences among the four states in the north-central region and applying or not applying a management practice (21). Estimates of an indicator variable are interpreted relative to the reference group (the group for which the indicator variable takes the value 0 in Table 1) (21). Also, an indicator variable can interact with the quantitative input variables, e.g., weather variables, allowing for the slopes of the quantitative variables to differ across different groups (21).

The use of indicator variables allows for the data to be pooled and analyzed together while differences among subgroups are still distinguishable (21). Pooling the data is necessary for identifying significant effects since a large number of degrees of freedom is available (36). This might not be possible if separate models for each state had been considered due to limited data (36), such as the presence of Sclerotinia stem rot in only two fields in Illinois and two fields in Ohio, respectively. However, the results for SSR prevalence and yield quantification are for simplicity presented separately for each state. Differences among models on the estimates of the same parameters are the products of statistically significant values of indicator variables or the interactions between indicator and quantitative variables.

There were two differences between the prevalence and the yield models in input variables: (i) The yield model included September air temperature and precipitation, since previous studies showed the importance of these variables for yield $(11,18)$, while the SSR prevalence model excluded September air temperature and precipitation, since in fall the disease has already occurred. (ii) In the yield model,

Table 1. List of variables used in soybean Sclerotinia stem rot (caused by Sclerotinia sclerotiorum) prevalence model and yield quantification in the northcentral region of the United States

\begin{tabular}{|c|c|c|c|}
\hline Variable type & Variable description & Category definitions ${ }^{x}$ & Unit \\
\hline \multicolumn{4}{|c|}{ Management practices } \\
\hline & Seed treatment & $0:$ no seed trt, 1 : seed trt & None \\
\hline & Manure & 0 : no manure, 1 : manure & None \\
\hline & Fertilizer & 0 : no fertilizer, 1 : fertilizer application & None \\
\hline & Herbicide application & 0: no herbicide, 1 : herbicide application & None \\
\hline & No-tilly ${ }^{y}$ & 0: minimum or conventional till, 1 : no-till & None \\
\hline & Min-tilly & 0 : odd passes, 1 : even passes & None \\
\hline & Conventional tilly & $0:$ more than $3,1:$ one, $2:$ two $, 3:$ three passes & None \\
\hline & Tillage $^{z}$ & 1: no-till, 2 : min-till, 3 : conventional till & None \\
\hline \multicolumn{4}{|c|}{ 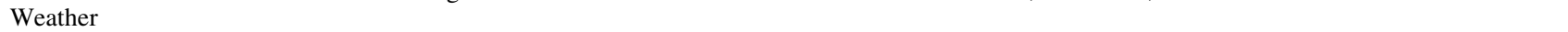 } \\
\hline & Average air temperature July and August & & ${ }^{\circ} \mathrm{C}$ \\
\hline & Air temperature September ${ }^{\mathrm{z}}$ & & ${ }^{\circ} \mathrm{C}$ \\
\hline & June precipitation & & $\mathrm{cm}$ \\
\hline & July precipitation & & $\mathrm{cm}$ \\
\hline & August precipitation & & $\mathrm{cm}$ \\
\hline & September precipitation ${ }^{\mathrm{z}}$ & & $\mathrm{cm}$ \\
\hline \multicolumn{4}{|l|}{ Soil texture } \\
\hline & Percentage of clay & & None \\
\hline & Percentage of silt & & None \\
\hline & Percentage of sand & & None \\
\hline \multicolumn{4}{|c|}{ Sclerotinia stem rot } \\
\hline & Prevalence & 0 : no, 1 : yes & None \\
\hline & Incidence $^{\mathrm{z}}$ & & None \\
\hline \multicolumn{4}{|l|}{ Other } \\
\hline & State effect & Illinois: 0, Iowa: 1, Minnesota: 2, Ohio: 3 & None \\
\hline & Erosion & $0:$ no, 1 : yes & None \\
\hline Yield & & & $\mathrm{kg} / \mathrm{ha}$ \\
\hline
\end{tabular}

${ }^{\mathrm{x}}$ Definitions are only for categorical variables.

y Used only in Sclerotinia stem rot prevalence model.

${ }^{\mathrm{z}}$ Used only in yield model. 
tillage practices were used as one categorical variable with conventional tillage as the reference group. In the SSR prevalence model, no-tillage, minimum tillage, and conventional tillage were considered as separate categorical variables. No-tillage was used as implementation or not, minimum tillage as even or odd number of passes, and conventional tillage as number of passes (one, two, three, or more than three). The reason for this differentiation in the use of tillage in yield and SSR prevalence models stems from studies on adoption of no-till technology that have shown that there is delay in no-till adoption primarily because of the high cost of replacing the existing conventional planter and of the cost of learning how to obtain high-crop yield with no-till technology (27). Thus, even high risk of SSR might not provide enough motivation to farmers for changing tillage to reduce SSR risk. However, farmers may still be willing to modify the chosen tillage (e.g., change the number of passes in minimum tillage) to differentiate the expected disease risk.

Decision theory under uncertainty. Two decision criteria are usually used when a farmer's behavior under uncertainty is examined: (i) expected profit maximization, which is the most common assumption made in the production economics literature and government stabilization policies, and (ii) expected utility maximization where it is hypothesized that farmers maximize their expected "utilities" (satisfaction) $(2,31,44)$. Expected utility maximization does not exclude expected profit maximization but rather includes it as a special case when a farmer is risk neutral. Profit maximization was used in the present study.

Decision theory involves enumerating all possible payoffs and selecting the action that provides the highest expected profit. This procedure can be described as:

$$
E[\Pi(\alpha, \theta)]=\max [\Sigma \Pi(\alpha, \theta) \cdot P(\theta)]
$$

where $\alpha$ denotes the management option, $\theta$ is SSR incidence in a field, $E(\Pi)$ stands for expected profit (given a chosen management practice and a level of SSR incidence). If no information about SSR inci- dence is available, a farmer will choose the management practice that maximizes his expected utility $E[\Pi(\alpha, \theta)]$ given the probability $P(\theta)$ of SSR incidence. Since no information for $\theta$ is available, $P(\theta)$ is the decision-maker's subjective estimation of SSR incidence deriving from personal experience (8).

Table 3. $t$ tests of null hypothesis of no significant difference of values of precipitation during June (Junpr), July (Julpr), August (Augpr), and September (Seppr) between the categories of each categorical variable $\mathrm{e}^{\mathrm{z}}$ that represent application of a management practice in fields sampled from Illinois (IL), Iowa (IA), Minnesota (MN), and Ohio (OH) in 1995 and 1996

\begin{tabular}{lllll}
\hline Treatment & Junpr & Julpr & Augpr & Seppr \\
\hline Seed treatment & 0.2 & 0.35 & $3.1 \mathrm{~b}$ & $2.85 \mathrm{~b}$ \\
Manure (liquid) & $2.9 \mathrm{~b}$ & 1.49 & 0.01 & $2.95 \mathrm{~b}$ \\
Manure (dry) & 0.46 & 1.06 & $2.05 \mathrm{~b}$ & 1.92 \\
No-till & 0.23 & 1.83 & $6.05 \mathrm{~b}$ & $2.56 \mathrm{~b}$ \\
Minimum-till & $2.95 \mathrm{~b}$ & 0.08 & $6.4 \mathrm{~b}$ & 0.38 \\
Conventional-till & $2.06 \mathrm{~b}$ & 1.83 & 1.7 & 0.54 \\
Fertilizer (IL) & 0.22 & 0.2 & $2.16 \mathrm{~b}$ & $13.1 \mathrm{~b}$ \\
Fertilizer (IA) & 0.76 & 0.68 & 0.25 & $42.8 \mathrm{~b}$ \\
Fertilizer (MN) & $4.5 \mathrm{~b}$ & 1.35 & 0.01 & $3.37 \mathrm{~b}$ \\
Fertilizer (OH) & 1.94 & 0.47 & 1.11 & $3.03 \mathrm{~b}$ \\
Weed cultivation (IA) & $2 \mathrm{~b}$ & $3.3 \mathrm{~b}$ & $5 \mathrm{~b}$ & $44.4 \mathrm{~b}$ \\
Weed cultivation (MN) & $3.14 \mathrm{~b}$ & 0.2 & $2.6 \mathrm{~b}$ & $10.2 \mathrm{~b}$ \\
\hline
\end{tabular}

${ }^{\mathrm{z}} \mathrm{b}$ indicates $t$ values significant at $P=0.05$.

Table 4. Parameter estimates of management practices and summer weather effects on prevalence of soybean Sclerotinia stem rot (SSR), caused by Sclerotinia sclerotiorum, and on soybean attainable yield in Iowa for 1995 and 1996

\begin{tabular}{|c|c|c|}
\hline Variable & $\begin{array}{c}\text { Parameter } \\
\text { estimate }^{\mathrm{z}}\end{array}$ & $\begin{array}{c}\text { Standard } \\
\text { error }\end{array}$ \\
\hline $\begin{array}{l}\text { SSR prevalence model } \\
\text { Seed treatment } \\
\text { Manure (liquid) } \\
\text { (July precipitation) } \times \text { (no-till) } \\
\text { Min-tillage (even against odd passes) } \\
\text { No-till } \\
\text { (Seed treatment) } \times \text { (clay) }\end{array}$ & $\begin{array}{l}-1.96 \mathrm{a} \\
3.8 \mathrm{c} \\
0.19 \mathrm{~b} \\
-0.63 \mathrm{a} \\
-2 \mathrm{c} \\
0.055 \mathrm{~b}\end{array}$ & $\begin{array}{l}0.83 \\
2.23 \\
0.09 \\
0.21 \\
1.18 \\
0.025\end{array}$ \\
\hline $\begin{array}{l}\text { Yield quantification } \\
\text { Intercept } \\
\text { SSR incidence }(\%) \\
\text { Average air temperature during July and August } \\
\text { June precipitation } \\
\text { July precipitation } \\
\text { August precipitation } \\
\text { September precipitation } \\
\text { Erosion } \\
\text { Manure (liquid) } \\
\text { No-till } \\
\text { Min-till } \\
\text { (Average air temperature during July and August) } \times \\
\text { (SSR incidence) } \\
\text { (Average air temperature during July and August) } \times \\
\text { (herbicide application) } \\
\text { (June precipitation) } \times(\text { no-till) } \\
\text { (June precipitation) } \times(\text { min-till) } \\
\text { (July precipitation) } \times(\text { clay) } \\
\text { (July precipitation) } \times(\text { seed treatment) }\end{array}$ & $\begin{array}{c}98.36 \mathrm{a} \\
-6.4 \mathrm{a} \\
-2.7 \mathrm{a} \\
0.5 \mathrm{a} \\
0.81 \mathrm{a} \\
0.28 \mathrm{a} \\
-0.4 \mathrm{a} \\
-1.66 \mathrm{~b} \\
4 \mathrm{~b} \\
4.56 \mathrm{c} \\
4.7 \mathrm{~b} \\
\\
0.3 \mathrm{a} \\
\\
1.16 \mathrm{c} \\
-0.53 \mathrm{a} \\
-0.4 \mathrm{~b} \\
-0.028 \mathrm{a} \\
0.51 \mathrm{a}\end{array}$ & $\begin{array}{r}18.18 \\
1.72 \\
0.74 \\
0.17 \\
0.24 \\
0.09 \\
0.12 \\
0.91 \\
2.11 \\
2.62 \\
2.23\end{array}$ \\
\hline
\end{tabular}

${ }^{\mathrm{z}} \mathrm{a}, \mathrm{b}$, and $\mathrm{c}$ indicate significance at $P=0.01,0.05$, and 0.1 , respectively.

Table 2. Contingency tables analysis of association between categorical variables that represent application of management practices in the fields sampled from Illinois (IL), Iowa (IA), Minnesota (MN), and Ohio (OH) in 1995 and $1996^{2}$

\begin{tabular}{|c|c|c|c|c|c|c|c|c|c|c|}
\hline \multirow[b]{2}{*}{ Treatment } & \multicolumn{2}{|c|}{ Minimum-tillage } & \multicolumn{2}{|c|}{ No-tillage } & \multicolumn{2}{|c|}{ Conventional tillage } & \multicolumn{2}{|c|}{ Seed treatment } & \multicolumn{2}{|c|}{ Manure } \\
\hline & $X^{2}$ & $P$ & $X^{2}$ & $P$ & $X^{2}$ & $P$ & $X^{2}$ & $P$ & $X^{2}$ & $P$ \\
\hline Herbicide application (IA) & 62 & $<0.0001$ & 60.3 & $<0.0001$ & 0.2 & 0.63 & 7.5 & 0.006 & 8.4 & 0.015 \\
\hline Herbicide application (MN) & 4.85 & $<0.027$ & 28.1 & $<0.0001$ & 20.6 & $<0.0001$ & 10.7 & 0.001 & 5.7 & 0.056 \\
\hline Fertilizer (IL) & 0.57 & $<0.45$ & 0.33 & $<0.56$ & 0.2 & 0.66 & 0.41 & 0.52 & 26.6 & $<0.0001$ \\
\hline Fertilizer (IA) & 31.9 & $<0.0001$ & 6.84 & 0.009 & 3.9 & 0.04 & 17.1 & $<0.0001$ & 17.4 & 0.0002 \\
\hline Fertilizer (MN) & 4.77 & $<0.029$ & 37.7 & $<0.0001$ & 34.4 & $<0.0001$ & 4.8 & 0.027 & 7.7 & 0.021 \\
\hline Fertilizer $(\mathrm{OH})$ & 34.4 & $<0.0001$ & 71 & $<0.0001$ & 0.3 & 0.59 & 68.3 & $<0.0001$ & 14.7 & 0.0006 \\
\hline Manure & 38.4 & $<0.0001$ & 28.2 & $<0.0001$ & 0.4 & 0.82 & 4.1 & 0.12 & $\ldots$ & \\
\hline Seed treatment & 4.2 & $<0.039$ & 5.3 & $<0.022$ & 0 & 0.99 & $\ldots$ & $\ldots$ & & \\
\hline
\end{tabular}

${ }^{\mathrm{z}}$ The null hypothesis of independence between two categorical variables was tested by a chi-square test. 
The farmer receives further information about the expected SSR prevalence in his area through a forecaster $z$ (SSR prediction model). The farmer updates his estimation $\theta$ by com-

bining his past experience with the information of the forecaster via Bayes' theorem:

$$
P(\theta \mid z) \propto P(\theta) \cdot P(z \mid \theta)
$$

Table 5. Parameter estimates of management practices and summer weather effects on prevalence of soybean Sclerotinia stem rot (SSR), caused by Sclerotinia sclerotiorum, and on soybean attainable yield in Ohio for 1995 and 1996

\begin{tabular}{|c|c|c|}
\hline Variable & $\begin{array}{c}\text { Parameter } \\
\text { estimate }^{\mathrm{z}}\end{array}$ & $\begin{array}{c}\text { Standard } \\
\text { error }\end{array}$ \\
\hline \multicolumn{3}{|l|}{ SSR prevalence model } \\
\hline Seed treatment & $-1.96 \mathrm{a}$ & 0.83 \\
\hline Manure (liquid) & $3.8 \mathrm{c}$ & 2.23 \\
\hline$($ July precipitation $) \times($ no-till $)$ & $0.19 \mathrm{~b}$ & 0.09 \\
\hline Min-till (even against odd passes) & $-0.63 \mathrm{a}$ & 0.21 \\
\hline No-till & $-2 \mathrm{c}$ & 1.18 \\
\hline$($ Seed treatment $) \times($ clay $)$ & $0.055 \mathrm{~b}$ & 0.025 \\
\hline \multicolumn{3}{|l|}{ Yield quantification } \\
\hline Intercept & $31.96 \mathrm{a}$ & 18.18 \\
\hline SSR incidence $(\%)$ & $-6.4 \mathrm{a}$ & 1.72 \\
\hline Average air temperature during July and August & $0.19 \mathrm{a}$ & 1.03 \\
\hline July precipitation & $0.81 \mathrm{a}$ & 0.24 \\
\hline August precipitation & $-0.19 \mathrm{a}$ & 0.16 \\
\hline September precipitation & $-0.4 \mathrm{a}$ & 0.12 \\
\hline Erosion & $-1.66 \mathrm{~b}$ & 0.91 \\
\hline Manure (liquid) & $4 \mathrm{~b}$ & 2.11 \\
\hline No-till & $4.56 \mathrm{c}$ & 2.62 \\
\hline Min-till & $4.7 \mathrm{~b}$ & 2.23 \\
\hline $\begin{array}{l}\text { (Average air temperature during July and August) } \times \\
\text { (SSR incidence) }\end{array}$ & $0.3 \mathrm{a}$ & 0.08 \\
\hline Herbicide application & $-9.08 \mathrm{a}$ & 3.82 \\
\hline Fertilizer & $-9.8 \mathrm{a}$ & 3.77 \\
\hline (June precipitation $) \times($ no-till $)$ & $-0.53 \mathrm{a}$ & 0.28 \\
\hline (June precipitation $) \times($ min-till $)$ & $-0.4 \mathrm{~b}$ & 0.19 \\
\hline (July precipitation $) \times($ clay $)$ & $-0.028 \mathrm{a}$ & 0.007 \\
\hline$($ July precipitation $) \times($ seed treatment $)$ & $0.51 \mathrm{a}$ & 0.21 \\
\hline (June precipitation $) \times($ fertilizer $)$ & $0.73 \mathrm{~b}$ & 0.32 \\
\hline (September precipitation $) \times($ Herbicide application $)$ & $1.58 \mathrm{a}$ & 0.66 \\
\hline
\end{tabular}

${ }^{\mathrm{z}} \mathrm{a}, \mathrm{b}$, and $\mathrm{c}$ indicate significance at $P=0.01,0.05$, and 0.1 , respectively.

Table 6. Parameter estimates of management practices and summer weather effects on prevalence of soybean Sclerotinia stem rot (SSR), caused by Sclerotinia sclerotiorum, and on soybean attainable yield in Illinois for 1995 and 1996

\begin{tabular}{lcc}
\hline Variable & $\begin{array}{c}\text { Parameter } \\
\text { estimate }^{\mathbf{z}}\end{array}$ & $\begin{array}{c}\text { Standard } \\
\text { error }\end{array}$ \\
\hline SSR prevalence model & & \\
Seed treatment & $-1.96 \mathrm{a}$ & 0.83 \\
Manure (liquid) & $3.8 \mathrm{c}$ & 2.23 \\
(July precipitation) $\times$ (no-till) & $0.19 \mathrm{~b}$ & 0.09 \\
Min-till (even against odd passes) & $-0.63 \mathrm{a}$ & 0.21 \\
No-till & $-2 \mathrm{c}$ & 1.18 \\
(Seed treatment) $\times($ clay) & $0.055 \mathrm{~b}$ & 0.025 \\
Fertilizer & $-1.67 \mathrm{c}$ & 1.01 \\
(August precipitation) $\times($ fertilizer) & $0.72 \mathrm{c}$ & 0.44 \\
Yield quantification & & \\
Intercept & $98.36 \mathrm{a}$ & 18.18 \\
SSR incidence $(\%)$ & $-6.4 \mathrm{a}$ & 1.72 \\
Average air temperature during July and August & $-2.7 \mathrm{a}$ & 0.74 \\
July precipitation & $0.81 \mathrm{a}$ & 0.24 \\
August precipitation & $0.28 \mathrm{a}$ & 0.09 \\
September precipitation & $-0.4 \mathrm{a}$ & 0.12 \\
Erosion & $-1.66 \mathrm{c}$ & 0.91 \\
Manure (liquid) & $4 \mathrm{~b}$ & 2.11 \\
No-till & $4.56 \mathrm{c}$ & 2.62 \\
Min-till & $4.7 \mathrm{~b}$ & 2.23 \\
(Average air temperature during July and August) $\times$ & & \\
(SSR incidence) & $0.3 \mathrm{a}$ & 0.08 \\
(June precipitation) $\times($ no-till) & $-0.53 \mathrm{a}$ & 0.28 \\
(June precipitation) $\times($ min-till) & $-0.4 \mathrm{~b}$ & 0.19 \\
(July precipitation) $\times($ clay) & $-0.028 \mathrm{a}$ & 0.007 \\
(July precipitation) $\times($ seed treatment) & $0.51 \mathrm{a}$ & 0.21 \\
(SSR incidence) $\times($ fertilizer) & $-1.11 \mathrm{a}$ & 0.41 \\
(September precipitation) $\times($ Herbicide application) & $0.69 \mathrm{~b}$ & 0.34 \\
\hline a and & &
\end{tabular}

${ }^{\mathrm{z}} \mathrm{a}, \mathrm{b}$, and $\mathrm{c}$ indicate significance at $P=0.01,0.05$, and 0.1 , respectively.
If $P(\theta \mid z)$ is the updated estimation; $P(\theta)$ is the past experience; and $P(z \mid \theta)$ is the forecast, then substituting the updated estimation of equation 3 into equation 2, we have:

$E(\Pi \mid \theta)=\max [\Sigma \Pi(\alpha, \theta) \cdot P(\theta \mid z)]$

Empirical data about how farmers interpret regional disease risk into within-field incidence are not available. It is suggested (58) that farmers weigh their past experiences, giving more weight to recent observations and less to those that occurred some time in the past. In the present case, past experiences are incorporated using the MAXIMIN or the MAXIMAX criterion (39). The MAXIMIN criterion corresponds to farmers with prior experience indicating that their fields are the ones under high SSR risk (e.g., farmers that experienced severe SSR infection the proceeding year). The MAXIMAX criterion corresponds to farmers with prior experience indicating that their fields are the ones under low SSR risk (e.g., farmers with no past experience with SSR) (40). Payoff tables are used to represent $E(\Pi)$, net profit, under different management practices-SSR scenarios $(32,39)$. In payoff tables, rows depict management options, and columns show expected net profits under different SSR incidence levels. In this study, we used four management practices (tillage, manure application, seed treatment, and combination of manure and seed treatment). For each management practice, we considered two options: apply the management practice or not, and three SSR incidence levels $(0,10$, and $60 \%)$. Iowa is used as an example, but a similar approach can be derived for all states. Expected SSR prevalence and yield with or without the management practices were estimated. The cost of manure application was obtained from the Department of Agricultural and Biosystems Engineering, ISU, the cost of seed treatment from Gustafson, TX, and the soybean price was a 10 -year average.

\section{RESULTS}

Correlation between variables. Three types of measure of associations were used in our analysis: (i) Correlation between continuous variables. There were significant negative correlations between percentage of sand and percentage of silt, and between percentage of sand and percentage of clay, significant positive correlation between air temperature of July and August, and significant negative correlation between temperature and precipitation of September. Due to these correlations, only the percentage of clay, September precipitation, and the average air temperature during July and August were selected as inputs in the models with management practices. After these modifications, remaining correlations between the continuous variables were not higher than 0.14 . (ii) Correlation between categorical variables. There were significant positive link- 
ages between the categorical variables (management practices) in most cases (Table 2). These linkages show a pattern in soybean production whereby farmers apply management practices in specific combinations. For example, herbicides, seed treatment, and manure were applied mostly in minimum- and no-till fields; in Iowa and Ohio, farmers who used treated seed also applied manure and fertilizer in their fields. (iii) Correlation between continuous and categorical variables. Most of the categorical variables (management practices) were significantly (95\% level of significance) correlated with the average air temperature during July and August, and August and September precipitation (Table 3). These correlations stem from the fact that there are differences among geographical regions with regard to applied management practices (e.g., most no-till fields are located in Illinois and most minimum-till fields are located in Minnesota). Correlations between categorical, and continuous and categorical variables were not used as a criterion to exclude variables from the model. These associations were used to interpret the results of the linear regression analysis.

SSR prevalence model. Seed treatment, application of liquid manure, and no-tillage or even versus odd number of passes in minimum-tillage were significant for all states. Fertilizer application in Illinois and Minnesota and weed cultivation in Minnesota were significant. The intercept was not significantly different from zero $(P=0.7)$. SSR prevalence models for each state are in Tables 4 through 7, where significant input variables $(P<0.1)$ are presented. Proportions of concordant and discordant pairs of fitted models were $88.7 \%$ for concordant and $11.0 \%$ for discordant pairs. The indices Somers' D, Gamma, and c were $0.78,0.78$, and 0.89 , respectively.

Soybean yield model. For all states, summer weather variables (average air temperature during July and August, and precipitation during June, July, August, and September), management practices, and interactions between management practices and weather accounted for $27 \%$ of yield variation. Low temperatures in July and August and high precipitation from June to September favored increased attainable yield. Application of herbicides and liquid manure increased yield. No or minimum tillage reduced attainable yield compared with conventional tillage. Disease incidence (percentage of soybean plants infected in individual fields) was negatively associated with yield depending on the average air temperature during July and August. Fields classified as highly erodible (HEL) yielded less than the other fields. Linear regression parameter estimates for significant input variables $(P<0.1)$ are presented in Tables 4 through 7. Plots of residuals against values of input variables or predicted values showed the appropriate scattered patterns.
Simulation of SSR prevalence and yield quantification. Examples of predicted disease prevalence and yield quantification generated with the parameter estimates (Tables 4 through 7) are in Figures 1 through 3. SSR prevalence was higher in minimum-till than in no-till fields when July precipitation was less than $7.5 \mathrm{~cm}$; although with higher precipitation, no-till fields could have lower or higher disease risk than minimum-till fields depending on the number of tillage passes (Fig. 1A). Manure application shifted up all the lines of SSR incidence (not shown), implying increased risk under any tillage regime after manure application. There was a difference in the expected yield between minimum and no-till fields, with minimum-till superior to no-till depending on June precipitation (Fig. 1B). This difference becomes even larger if manure is applied (about $268 \mathrm{~kg} / \mathrm{ha}$ ). Figure 2 shows the effects of applying and not applying herbicide on SSR prevalence (Fig. 2A and C) and soybean yield (Fig. 2B and D) under no-till in Minnesota. No-till fields with applied herbicides had higher probability of SSR than fields without herbicide application in low July and August tempera-

tures. In contrast, the SSR prevalence was expected to be lower in fields with applied herbicides than in fields without, especially if July and August average air temperature and July precipitation were high. Attainable yield (even when SSR incidence was $60 \%$ ) was higher with than without herbicides when average July and August air temperature is 22 to $24^{\circ} \mathrm{C}$ and July precipitation is 9 to $11 \mathrm{~cm}$. On the other hand, the herbicide effect was reversed for hot summers. However, in this case the probability of SSR prevalence was low.

The probability of SSR prevalence in treated soybean seed was always higher in clay than in sand soils for any range of July precipitation and becomes very high when the total July precipitation is high too (Fig. 3A). In sandy and clay soils, expected yield was higher with treated seed than with nontreated seed in any level of SSR incidence, and yield is estimated higher with low than with high percentage of clay soil content (Fig. 3B).

Decision under uncertainty. Farmers who frequently or recently have observed SSR in their fields would likely decide under the MAXIMIN criterion considering

Table 7. Parameter estimates of management practices and summer weather effects on prevalence of soybean Sclerotinia stem rot (SSR), caused by Sclerotinia sclerotiorum, and on soybean attainable yield in Minnesota for 1995 and 1996

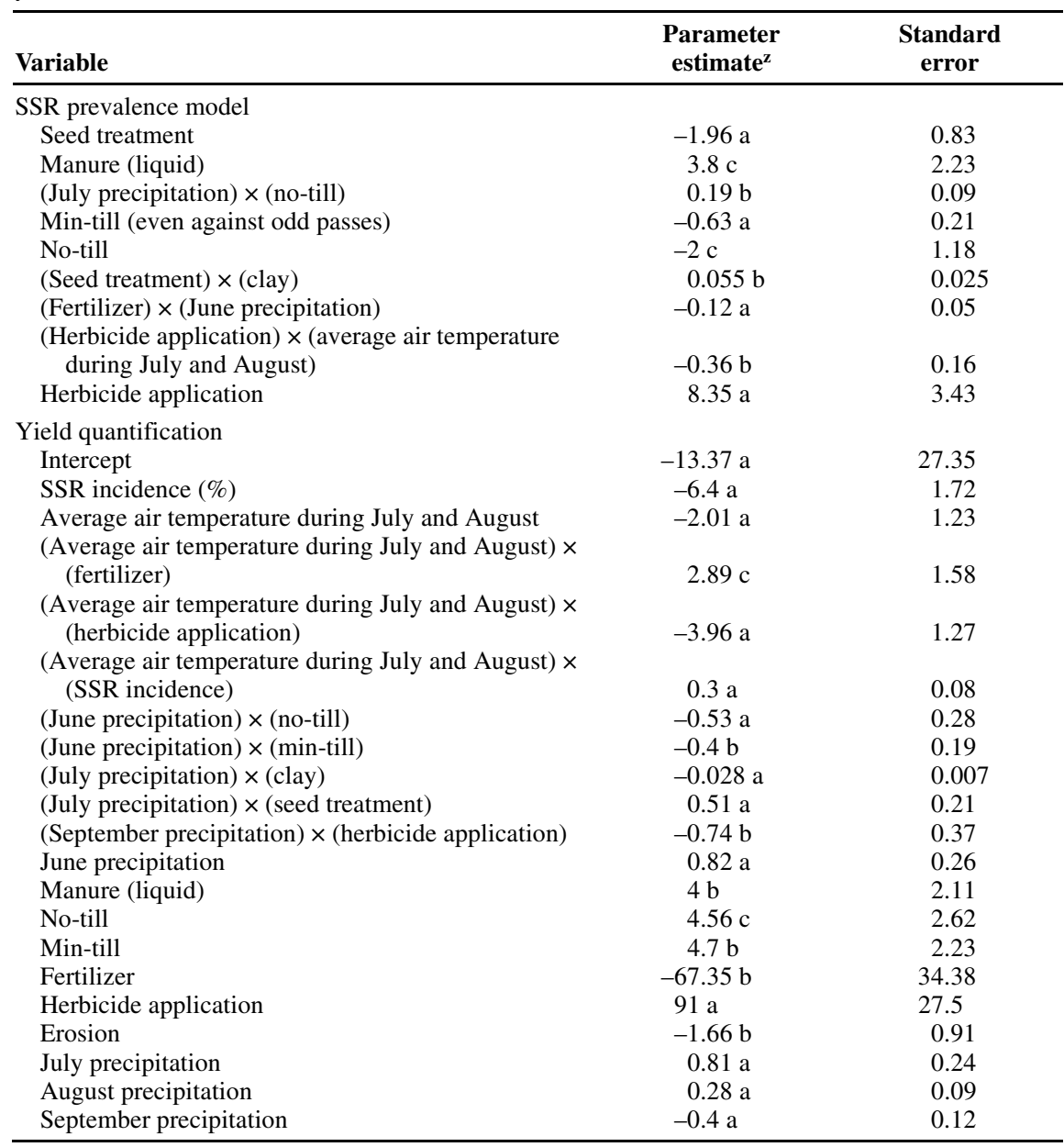

${ }^{\mathrm{z}} \mathrm{a}, \mathrm{b}$, and $\mathrm{c}$ indicate significance at $P=0.01,0.05$, and 0.1 , respectively. 
that the worst scenario will occur: their fields will be at high risk for SSR, even if predicted SSR prevalence in their area is low. For example, expected prevalence when manure and treated seed are used is high (0.8), but much lower when these practices are not applied (0.3) (Table 8). Farmers of the MAXIMIN group consider their fields to be among the 8 of 10 fields with high SSR incidence if manure and treated seed are used or among the 3 of 10 fields with high SSR incidence if manure and treated seed are not used. For these farmers, profit is maximized when management practices are applied (Table 8, choose row yes for management practices and column 10 or $60 \%$ for incidence).

Farmers with no or rare previous SSR records in their fields will make the most optimistic choice: no SSR will be found in their fields even if predicted SSR prevalence in their area is high. These farmers consider themselves belonging to the low risk group ( 3 of 10 fields with SSR if manure and treated seed are not used or 8 of 10 fields with SSR if manure and treated seed are used) and will choose management practices to maximize their profit (Table 8, choose row no for management practices and column $0 \%$ for incidence).

\section{DISCUSSION}

Our results suggest that SSR is a disease associated with management practices and weather conditions that are favorable to high attainable yield. Management practices, such as seed treatment, manure, fertilizer, and herbicide application, are associated with high attainable yield and SSR prevalence (Table 9). Frequent SSR occurrence in fields with high yield potential has been suggested in other studies as well $(19,29)$. However, this association has been attributed mainly to factors such as narrow
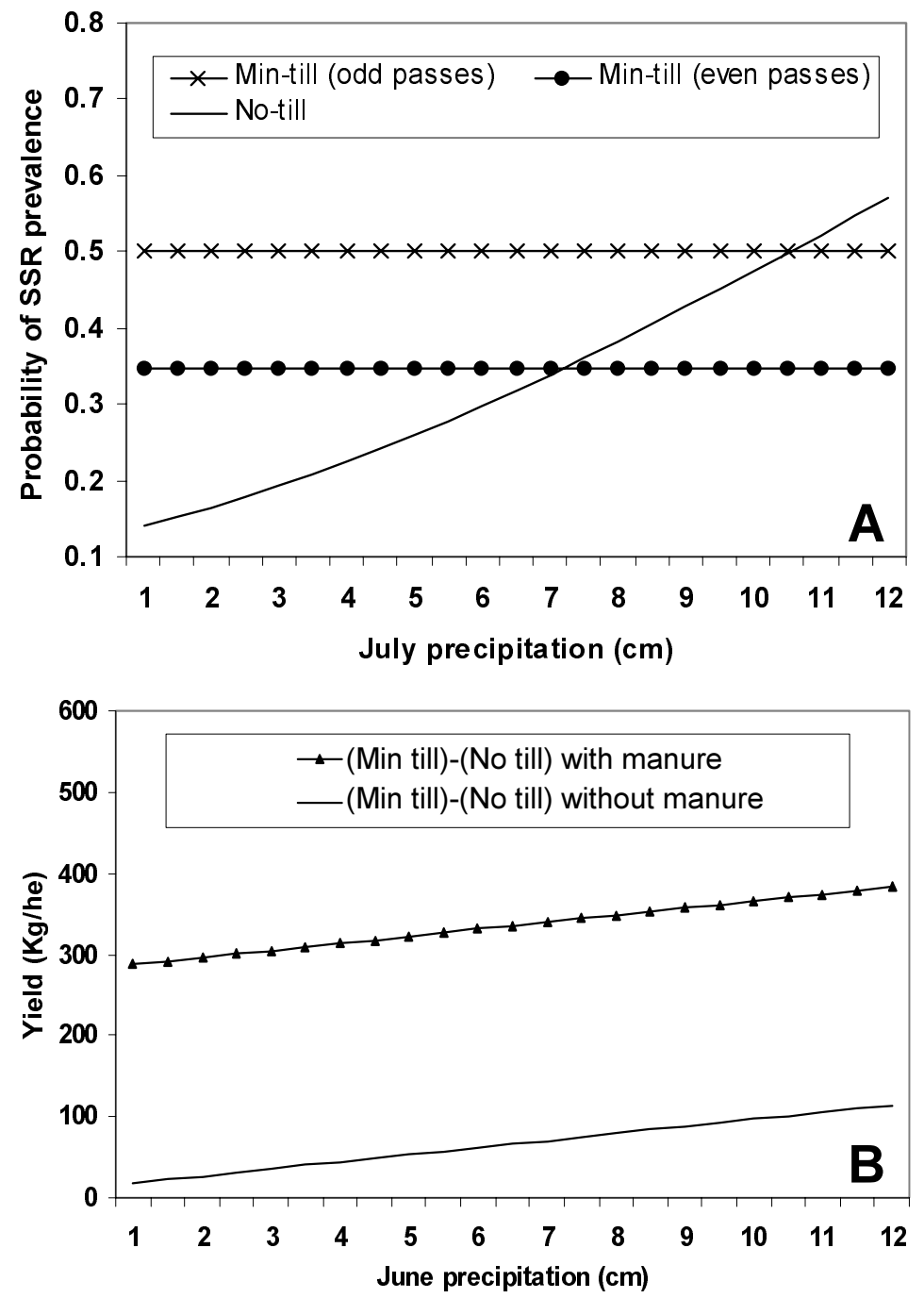

Fig. 1. A, Probability of Sclerotinia stem rot (SSR) prevalence, caused by Sclerotinia sclerotiorum, in no- or minimum-till (even and odd passes) soybean fields with July precipitation, using the parameter estimates in Table 4. Seed treatment and manure application were equal to zero (no application). B, Difference in expected yield between no- and minimum-till fields with or without manure application, using the parameter estimates of Iowa yield quantification (Table 4). For the calculations, July, August, and September precipitation was considered equal to $6 \mathrm{~cm}$, average air temperature of July and August was equal to $20^{\circ} \mathrm{C}$, clay content was equal to $30 \%$, and seed treatment and SSR incidence were equal to 0 . planting rows and high plant populations that promote dense soybean canopy (26). Dense canopy creates high moisture and low temperature within the canopy, conditions favorable for SSR development $(5,6)$.

Low average air temperature during July and August and high July precipitation are associated with increased soybean yield. This finding agrees with previous economic and agronomic studies. A study using historical yield data for the period 1891 to 1973 for the states of Iowa, Illinois, Indiana, and Missouri found that the expected yield during a drought period was less than that for a wet period (4). Soybean yield models developed by the Climatic and Environmental Assessment Services (CEAS) for Illinois, Indiana, and Iowa predict that low temperature and high soil moisture during summer increase yield $(15,30)$. This temperature-moisture combination has been reported to be favorable for SSR development in soybean $(6,19,33)$.

SSR prevalence is higher in minimum tillage than conventional tillage (33), although the risk varies with the number of tillage passes (Fig. 1A) and is lower in no tillage compared with conventional tillage. Kurle et al. (29) observed fewer apothecia in no tillage than in plowed fields, but they concluded that differences in SSR incidence among tillage systems are mainly attributable to differences in observed plant stand and canopy density. Similarly, Gracia-Garza et al. (16) suggested that environmental and microclimatic conditions in reduced tillage, such as high soil moisture, low soil temperature, and high nutrient availability are conducive to SSR development.

Lower attainable yield is found in reduced- or no-till fields more often than in conventional fields, although the overall effect depends on the amount of June precipitation. It is positive when June precipitation is low and negative when June precipitation is high. These results agree with previous studies $(25,27)$. Higher yield was found with no-till than with conventionaltill in dry years, probably because of conservation of more soil moisture in no-till fields than in conventional fields (25). It has been reported (29) that canopy development in no tillage is poorer than in conventional tillage, which should be a contributing factor to the yield differences observed among different tillage systems.

Application of liquid manure increases SSR risk and soybean attainable yield. Farmers in Michigan have observed higher disease incidence in areas where liquid manure was applied than in the rest of the state (37). Field experiments in Iowa showed that the number of apothecia was higher in plots where liquid manure had been applied than in nontreated plots (37). Also, Ferraz et al. (12) observed abundant apothecia production in high organic matter soils. It is plausible that the effect of manure is indirect since manure promotes 
vigorous plant growth that in turn creates a favorable environment for infection under the canopy. We note that the results we report correspond to liquid manure application. A similar relationship was not found in the case of dry manure application.

Seed treatment is negatively associated with disease prevalence, but its effect depends on the percentage of clay in the field. Fungicidal seed treatments may prevent the dissemination of $S$. sclerotiorum in new fields $(23,57)$. Seed treatment results in better stand establishment by preventing seedling disease problems, especially in wet conditions, than nontreated seeds $(13,32)$, consequently resulting in a dense canopy favorable to SSR development $(5,42,46)$.
In Illinois and Minnesota, fertilizer and its interaction with August precipitation were factors with a significant effect on SSR prevalence and attainable yield. Based on the 30-year average (1961 to 1991) for August precipitation in Illinois, the overall fertilizer effect was positive on SSR prevalence and negative on attainable yield. In Minnesota, based on the 30-year average air temperature during July and August, the effect of fertilizer was negative on SSR prevalence and on attainable yield. In Minnesota, the herbicide application had a positive effect on SSR prevalence and the attainable yield.

Fertilizer applications had no effect or increased slightly sclerotia germination (51), while in another study (12) fertilizer increased significantly the number of pro- duced apothecia. The potential effect of fertilizer applications on SSR development is attributed to the vigorous plant growth and dense canopy (12,52). Our results indicate that fertilizer effect on SSR occurrence is inconsistent among states. Herbicide applications (e.g., Lactofen) have been reported to reduce SSR incidence $(7,10)$. Less closure in canopy and hypersensitive response-type mechanisms have been proposed as explanations for the herbicide application effect $(7,10)$. However, in our study herbicides increased SSR risk in Minnesota. Since the exact applied herbicides are not known, we cannot conclude whether this result is an artifact of the data set or not. Fertilizer and herbicide applications are generally associated with high potential yield. Thus, the negative relation-
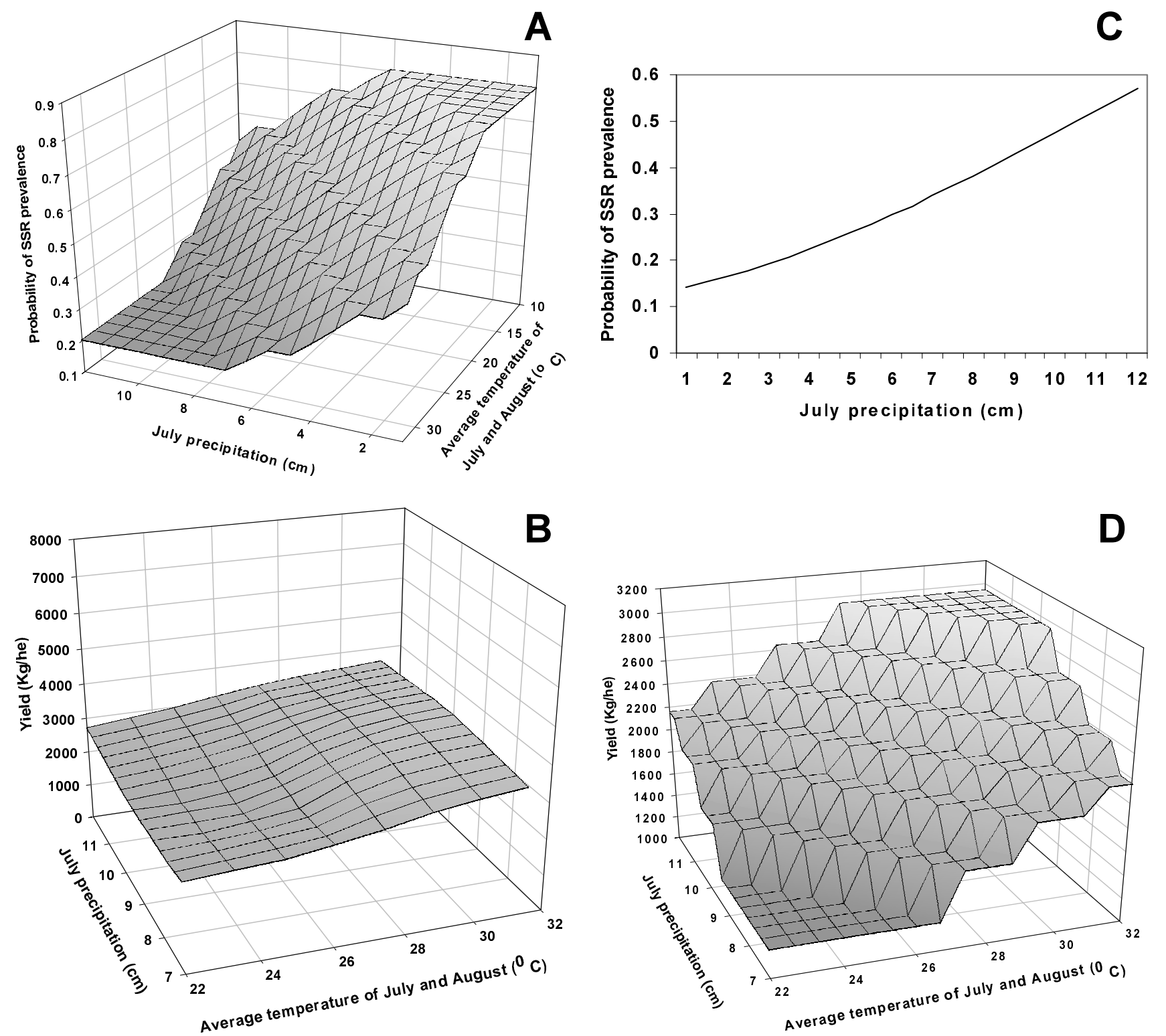

Fig. 2. A, Probability of Sclerotinia stem rot (SSR) prevalence, caused by Sclerotinia sclerotiorum, and B, soybean yield in no-till fields in Minnesota with herbicide application, using the parameter estimates in Table 7. C, Probability of SSR prevalence, caused by Sclerotinia sclerotiorum, and D, soybean yield in no-till fields in Minnesota without herbicide application, using the parameter estimates in Table 7. For all calculations, June, July, August, and September precipitation was considered equal to $12 \mathrm{~cm}$, clay content was equal to $30 \%$, SSR incidence was equal to $60 \%$, seed treatment, fertilizer, and manure applications were equal to 0 . 

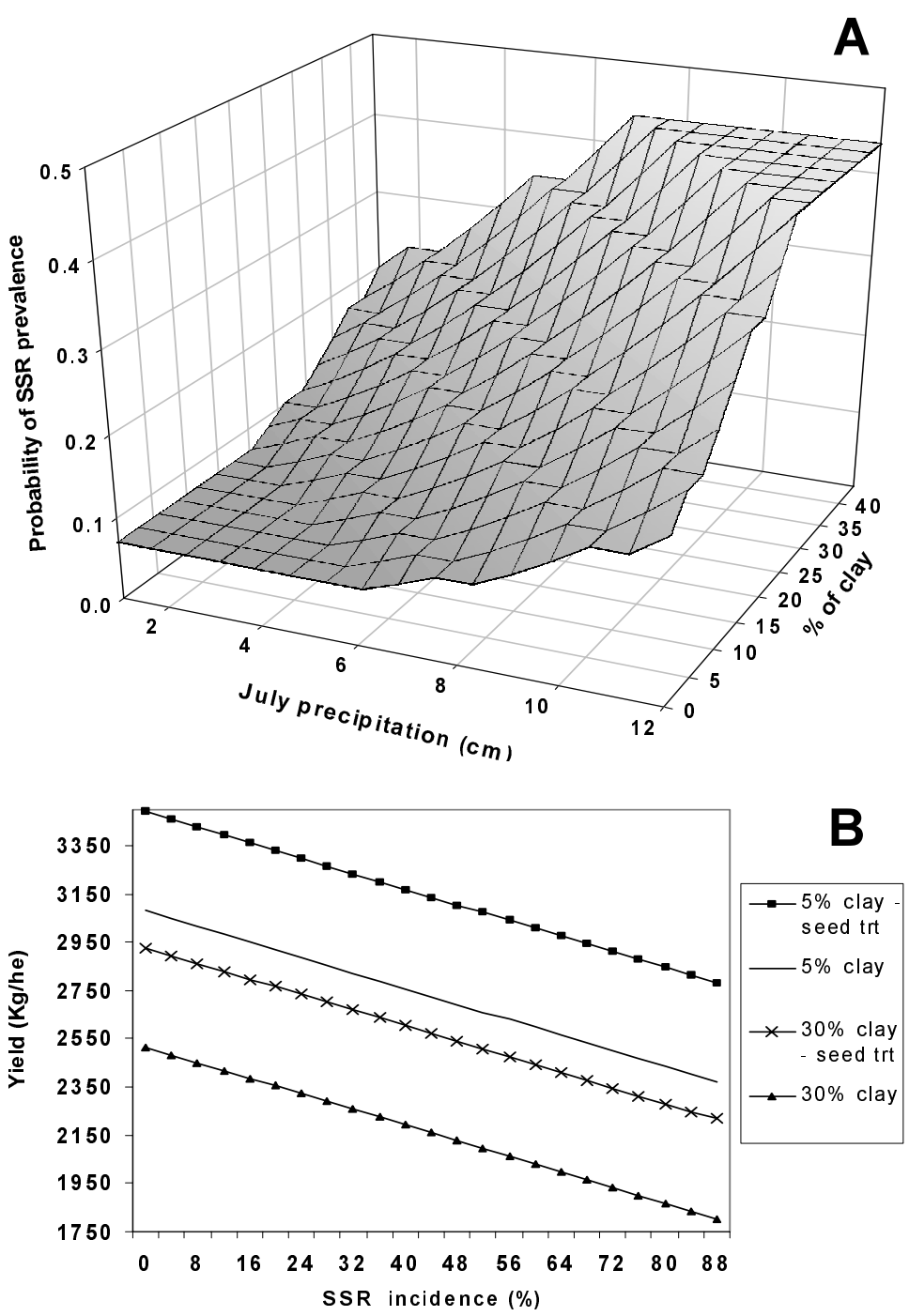

Fig. 3. A, Probability of Sclerotinia stem rot (SSR) prevalence, caused by Sclerotinia sclerotiorum, in no-till fields with seed treatment, using the estimated parameters in Table 6. B, Yield calculated using parameter estimates for Illinois yield quantification (Table 6) in no-till fields with or without seed treatment and different levels of SSR incidence. For all calculations, June, July, August, and September precipitation was considered equal to $12 \mathrm{~cm}$, average air temperature of July and August was equal to $20^{\circ} \mathrm{C}$, clay content was equal to 5 or $30 \%$, seed treatment, fertilizer, herbicide, and manure applications were equal to 0 . ship found between fertilizer application and yield in Illinois and Minnesota cannot be justified, but for the case that fertilizers were applied only in low potential yield fields in these two states.

There are two points to be addressed in the present study. First, weather data were collected from weather stations in a few cases located a considerable distance from the fields, and thus these weather data may not describe the precise environmental conditions experienced by the soybean plants. This might be one of the reasons for the low $R^{2}$ in the yield quantification. However, such macro-scale weather data have been used in studies to quantify yield $(15,18,30)$ or to describe regional patterns $(9,47,50)$ with good results. Our objective was only to describe the regional SSR pattern and examine whether there is an association between presence of SSR and high yield. Second, information about presence of inoculum of $S$. sclerotiorum in individual sampled fields was not available. Thus, the analysis was based on an assumption that presence of inoculum of $S$. sclerotiorum was equally probable in each of the sampled fields.

We concluded that if farmers' decisions are based on profit maximization and farmers weigh highly their past experience with the disease, they will apply the management practices that maximize their profit, and thus increase the risk for SSR occurrence, since high-yielding management practices are also inductive to SSR development. Nevertheless, these conclusions are drawn neglecting the effect that these management practices may have on SSR incidence. Profit is much lower when SSR incidence in a field is $60 \%$ than $10 \%$ (Table 8). Under this perspective, farmers may follow a different decision pathway. In economic terms, this means that farmers decide using the mean-variance criterion: they are willing to sacrifice part of their expected income to reduce the variance in income generated by different SSR inci-

Table 8. Pay-off table representing the net profit from applying or not applying no-till, minimum-till, manure, or using treated seed in Iowa and zero, low, or high Sclerotinia stem rot (SSR) incidence ${ }^{u}$

\begin{tabular}{|c|c|c|c|c|c|c|c|c|}
\hline \multirow[b]{2}{*}{ Application ${ }^{v}$} & \multirow[b]{2}{*}{ Response $^{w}$} & \multirow{2}{*}{$\begin{array}{c}\text { SSR } \\
\text { prevalence }^{\mathrm{x}}\end{array}$} & \multicolumn{2}{|c|}{ SSR incidence $0 \%$} & \multicolumn{2}{|c|}{ SSR incidence $10 \%$} & \multicolumn{2}{|c|}{ SSR incidence $60 \%$} \\
\hline & & & Yield (kg/ha) & Profit/ha $(\$)^{y}$ & Yield (kg/ha) & Profit/ha (\$) & $\overline{\text { Yield (kg/ha) }}$ & Profit/ha (\$) \\
\hline Manure application & Yes & 0.83 & 2,370 & 847 & 2,211 & 709 & 1,418 & 505 \\
\hline in no-tilled fields & No & 0.24 & 2,211 & 796 & 2,053 & 739 & 1,260 & 454 \\
\hline Seed treatment & Yes & 0.78 & 2,370 & 852 & 2,211 & 795 & 1,418 & 509 \\
\hline in no-tilled fields & No & 0.80 & 2,248 & 810 & 2,090 & 753 & 1,297 & 467 \\
\hline Manure application and & Yes & 0.80 & 2,370 & 846 & 2,211 & 789 & 1,418 & 503 \\
\hline $\begin{array}{l}\text { seed treatment } \\
\text { in no-tilled fields }\end{array}$ & No & 0.30 & 2,090 & 753 & 1,931 & 695 & 1,138 & 410 \\
\hline No-till & & 0.69 & 2,090 & 752 & 1,931 & 695 & 1,138 & 410 \\
\hline Min-till (even passes) ${ }^{\mathrm{z}}$ & & 0.73 & 2,126 & $(771-3 * n)$ & 1,968 & $(714-3 * n)$ & 1,175 & $(429-3 * n)$ \\
\hline Min-till (odd passes) & & 0.76 & 2,126 & $(771-3 * n)$ & 1,968 & $(714-3 * n)$ & 1,175 & $(429-3 * n)$ \\
\hline
\end{tabular}

" Parameter estimates from Table 4 were used for the calculations.

${ }^{\vee}$ Cost of manure application was $\$ 6.07 / \mathrm{ha}$. Cost of seed treatment was $\$ 1.60 / \mathrm{ha}$. Cost of seed treatment and manure application was $\$ 7.67 / \mathrm{ha}$. Cost of one pass in min-till was $\$ 2.60 /$ ha.

w Farmer's choice to apply management practice or not based on estimation of disease risk and past experience.

${ }^{x}$ Precipitation for every month was set at $6 \mathrm{~cm}$, average air temperature during July and August was set at $20^{\circ} \mathrm{C}$, and clay content was set at $30 \%$.

y Soybean price used for profit calculations was the average price for the period 1980 to 2000 received by Iowa farmers in October $(\$ 5.71 / \mathrm{bu})$.

${ }^{\mathrm{z}} n=$ number of passes in min-till. 
Table 9. Relationship between summer weather, management practices, and prevalence of Sclerotinia stem rot (SSR), caused by Sclerotinia sclerotiorum, or summer weather, management practices, and attainable soybean yield in four states (Illinois, Iowa, Minnesota [MN], and Ohio) of the north-central region of the United States

\begin{tabular}{lcc}
\hline Variable & $\begin{array}{c}\text { SSR prevalence } \\
\text { model }\end{array}$ & $\begin{array}{c}\text { Yield } \\
\text { quantification }\end{array}$ \\
\hline Average air temperature during July and August & - - $^{\mathrm{y}, \mathrm{y}}$ & $-^{\mathrm{x}, \mathrm{y}}$ \\
July precipitation & - & $+^{\mathrm{y}}$ \\
Seed treatment & + & + \\
Manure (liquid) & $-\mathrm{y}, \mathrm{z}$ & + \\
No-till (compared with conventional tillage) & $++^{\mathrm{y}, \mathrm{z}}$ & $-\mathrm{y}, \mathrm{z}$ \\
Minimum-till (compared with conventional tillage) & - & - \\
Fertilizer (MN) & + & + \\
Herbicide (MN) & & \\
\hline
\end{tabular}

$\mathrm{x}_{-}=$negative and $+=$positive relationship, respectively.

y Relationship of weather and tillage with SSR prevalence is based on results from the present study and results from Mila et al. (33) and Wrather et al. (55).

${ }^{\mathrm{z}}$ Relationship of no- and minimum-tillage with attainable yield can be positive when precipitation in June is low.

dence levels (8). Then utility rather than profit maximization is an accurate predictor of a farmer's decision (31). Future investigation is needed on the usefulness, if any, of macro-scale measures such as disease prevalence in site-specific decisions.

\section{ACKNOWLEDGMENTS}

Journal Paper No. J-19780 of the Iowa Agriculture and Home Economics Experiment Station, Ames, IA, Project No. 2869, and supported by Hatch Act and State of Iowa funds. This manuscript is a portion of A. L. Mila's Ph.D. thesis submitted to the graduate college of Iowa State University. We thank S. Savary and A. Wrather for critically reviewing the manuscript before submission.

\section{LITERATURE CITED}

1. Adams, P. B., and Ayes, W. A. 1979. Ecology of Sclerotinia species. Phytopathology 69:896-899.

2. Anderson, J. R., Dillon, J. L., and Hardaker, J. B. 1977. Agricultural Decision Analysis. Iowa State University Press, Ames, IA.

3. Anonymous. 1998. Crop Residue Management: Midwest Region. Conservation Technology and Information Center, West Lafayette, IN.

4. Black, J. R., and Thompson, S. R. 1978. Some evidence on weather-crop-yield interaction. Am. J. Agric. Econ. 60:540-543.

5. Blad, B. L., Steadman, J. R., and Weiss, A. 1978. Canopy structure and irrigation influence white mold disease and microclimate of dry edible beans. Phytopathology 68:14311437.

6. Boland, G. J., and Hall, R. 1988. Epidemiology of Sclerotinia stem rot of soybean in Ontario. Phytopathology 78:1241-1245.

7. Burnside, O. C., Wiens, M. J., Krause, N. H., Weisberg, S., Ristau, E. A., Johnson, M. M., and Sheets, R. A. 1998. Mechanical and chemical weed control systems for kidney bean (Phaseolus vulgaris). Weed Technol. 12:174-178.

8. Carlson, G. A. 1972. A decision theoretic approach to crop disease prediction and control. Am. J. Agric. Econ. 54:216-223.

9. Chester, K. S. 1946. The nature and prevention of the cereal rusts. Chronica Botanica Co., Waltham, MA

10. Dann, E. K., Diers, B. W., and Hammerschmidt, R. 1999. Suppression of Sclerotinia stem rot of soybean by lactofen herbicide treatment. Phytopathology 89:598-602.

11. Doupnik, B., Jr. 1993. Soybean production and disease loss estimates for north central United States from 1989 to 1991. Plant Dis. 77:1170-1171.
12. Ferraz, L. C., Café Filho, A. C., Nasser, L. C., and Azevedo, J. 1999. Effects of soil moisture, organic matter and grass mulching on the carpogenic germination of sclerotia and infection of bean by Sclerotinia sclerotiorum. Plant Pathol. 48:77-82.

13. Ferriss, R. S., Stuckey, R. E., Gleason, M. L., and Siegel, M. R. 1987. Effects of seed quality, seed treatment, soil source, and initial soil moisture on soybean seedling performance. Phytopathology 77:140-148.

14. Fox, G., Weersink, A., Sarwar, G., Duff, S., and Deen, B. 1991. Comparative economics of alternative agricultural production systems: A review. Northeastern J. Agric. Res. Econ. 20:125-139.

15. French, V. 1982. Evaluation of the CEAS trend and monthly weather data models for soybean yields in Iowa, Illinois, and Indiana. Lyndon B. Johnson Space Center, Houston, TX; NASA, Springfield, VA.

16. Gracia-Garza, J. A., Boland, G. J., and Vyn, T. J. 2002. Influence of crop rotation and reduced tillage on white mold of soybean caused by Sclerotinia sclerotiorum. Can. J. Plant Pathol. 24:115-121.

17. Grau, C. R., and Binssonnett, H. L. 1974. Whetzelinia stem rot of soybean in Minnesota. Plant Dis. Rep. 58:693-695.

18. Grau, C. R., and Hartman, G. L. 1999. Sclerotinia stem rot. Pages 46-48 in: Compedium of Soybean Diseases. G. L. Hartman, J. B. Sinclair, and J. C. Rupe, eds. 4th ed. American Phytopathological Society, St. Paul, MN

19. Grau, C. R., and Radke, V. L. 1984. Effects of cultivars and cultural practices on Sclerotinia stem rot of soybean. Plant Dis. 68:56-58.

20. Grau, C. R., Radke, V. L., and Gillespie, F. L. 1982. Resistance of soybean cultivars to Sclerotinia sclerotiorum. Plant Dis. 66:506-508.

21. Hardy, M. A. 1993. Regression with dummy variables. Sage University Papers Series. Sage Publications, London.

22. Hass, J. H., and Bolwyn, B. 1972. Ecology and epidemiology of Sclerotinia wilt of white beans in Ontario. Can. J. Plant Sci. 52:525533.

23. Herd, G. W., and Phillips, J. L. 1988. Control of seed-borne Sclerotinia sclerotiorum by fungicidal treatment of sunflower seed. Plant Pathol. 37:202-205.

24. Hosmer, D., and Lemeshow, S. 1989. Applied Logistic Regression. John Wiley \& Sons, New York.

25. Hussain, I., Olson, K. R., and Ebelhar, S. A. 1999. Impacts of tillage and no-till on production of maize and soybean on an eroded Illinois silt loam soil. Soil Till. Res. 52:37-49.

26. Joye, G. F., Berggren, G. T., and Berner, D. K. 1990. Effects of row spacing and within-row plant population on Rhizoctonia aerial bligh of soybean and soybean yield. Plant Dis. 74:158-160.

27. Krause, M. A., and Black, J. R. 1995. Optimal adoption strategies for no-till technology in Michigan. Rev. Agric. Econ. 17:299-310.

28. Kurkalova, L. A., Kling, K. L., and Zhao, J. 2001. The Subsidy for Adopting Conservation Tillage: Estimation from Observed Behavior. Center for Agriculture and Rural Development. Working Paper 01-WP 286, Iowa State University, Ames, IA.

29. Kurle, J. E., Grau, C. R., Oplinger, E. S., and Mengistu, A. 2001. Tillage, crop sequence, and cultivar effects on sclerotinia stem rot incidence and yield in soybean. Agron. J 93:973-982.

30. Le Duc, S. 1982. Crop weather models of corn and soybeans for agrophysical units (APU's) in Iowa using monthly meteorological predictors. Lyndon B. Johnson Space Center, Houston, TX; NASA, Springfield, VA.

31. Lin, W., Dean, G. W., and Moore, C. V. 1974 An empirical test of utility vs. profit maximization in agricultural production. Am. J. Agric. Econ. 56:497-508.

32. Lueschen, W. E., Evans, S. D., Ford, J. H., Hoverstand, T. R., Kanne, B. K., Orf, J. H., Staricka, J. A., Stienstra, W. C., Warnes, D D., and Hicks, D. R. 1991. Soybean production affected by tillage in a corn and soybean management system: II. Seed treatment response. J. Prod. Agric. 4:580-585.

33. Mila, A. L., Yang, X. B., Carriquiry, A. L., and Zhao, J. 2001. Modeling the prevalence of soybean Sclerotinia stem rot and the associated economic outcomes in the North Central Region of USA. Proc. 8th Int. Workshop Plant Epidemiol., Ouro Preto, Brazil.

34. Mueller, J. D., Cline, M. N., Sinclair, J. B., and Jacobsen, B. J. 1985. An in vitro test for evaluation efficacy of mycoparasites on sclerotia of Sclerotinia sclerotiorum. Plant Dis. 69:584-586.

35. Nelson, B. D., Helms, T. C., and Olson, M. A. 1991. Comparisons of laboratory and field evaluations of resistance in soybean of Sclerotinia sclerotiorum. Plant Dis. 75:662665.

36. Neter, J., and Wasserman, W. 1974. Applied Linear Statistical Models. Richard D. Irwin, Inc., Homewood, IL.

37. Oelke, L. H. 1998. Phytophthora root rot, damping-off, Sclerotinia stem rot and brown stem rot of soybeans in response to swine manure applications. M.S. thesis. Iowa State University, Ames, IA.

38. Oriade, C. A., Dillon, C. R., Vories, E. D., and Bohanan, M. E. 1997. An economic analysis of alternative cropping and row spacing systems for soybean production. J. Prod. Agric. 10:619-624.

39. Pauler, S. G., and Kassirer, J. P. 1987. Decision analysis. N. Engl. J. Med. 316:250-258.

40. Savary, S., Elazegui, F. A., Moody, K., and Teng, P. S. 1994. Characterization of rice cropping practices and multiple pest systems in the Philippines. Agric. Syst. 46:385-408.

41. Savary, S., Willocquet, L., Elazegui, F. A., Teng, P. S., Du, P. V., Zhu, D., Tang, Q., Huang, S., Lin, X., Singh, H. M., and Srivastava, R. K. 2000. Rice pest constraints in tropical Asia: Characterization of injury profiles in relation to production situations. Plant Dis. 84:341-356.

42. Schwartz, H. F., and Steadman, J. R. 1978 Factors affecting sclerotium populations of, and apothecium production by, Sclerotinia sclerotiorum. Phytopathology 68:383-388.

43. Shah, S. J., Hussain, S., Ali, A., and Khattak, I. 1992. Effect of different seed dressing fungicides on germination and yield components of soybean. Sarhad J. Agric. 8:679-682. 
44. Simon, H. A. 1958. Theories of decision making in economics and behavioral science. Am. Econ. Rev. 49:253-283.

45. Steadman, J. R. 1979. Control of plant diseases caused by Sclerotinia species. Phytopathology 69:904-907.

46. Steadman, J. R., Coyne, P. D., and Cook, G. E. 1973. Reduction of severity of white mold disease on great northern beans by wider spacing and determinate plant growth habit. Plant Dis. Rep. 57:1070-1071.

47. Stevens, N. E. 1934. Stewart's disease in relation to winter temperatures. Plant Dis. Rep. 18:141-149.

48. Teng, S. P., and Yuen, J. E. 1991. Epidemic models: Lessons from plant pathology. Pages 272-296 in: Risk Assessment in Genetic Engineering. M. Levin and H. Strauss, eds. McGraw-Hill, New York.

49. Tu, J. C. 1988. The role of white moldinfected white bean (Phaseolus vulgaris L.) seeds in the dissemination of Sclerotinia scle- rotiorum (Lib.) de Bary. J. Phytopathol. 121:40-50.

50. Wallin, J. R. 1964. Summer weather conditions and wheat stem rust in the Dakotas, Nebraska, and Minnesota. Int. J. Biometeorol. 8:39-45.

51. Williams, J. R., and Stelfox, D. 1980. Influence of farming practices in Alberta on germination and apothecium production of sclerotia of Sclerotinia sclerotiorum. Can. J. Plant Pathol. 2:169-172.

52. Workneh, F., Tylka, G. L., Yang, X. B., Faghihi, J., and Ferris, J. M. 1999. Regional assessment of soybean brown stem rot, Phytophthora sojae, and Heterodera glycines using area-frame sampling: Prevalence and effects of tillage. Phytopathology 89:204-211.

53. Workneh, F., and Yang, X. B. 2000. Prevalence of Sclerotinia stem rot of soybeans in the north-central United States in relation to tillage, climate, and latitudinal positions. Phytopathology 90:1375-1382.
54. Workneh, F., Yang, X. B., and Tylka, G. L. 1999. Soybean brown stem rot, Phytophthord sojae, and Heterodera glycines affected by soil texture and tillage relations. Phytopathology 89:844-850.

55. Wrather, J. A., Anderson, T. R., Arsyad, D. M., Gai, J., Plopper, L. D., Porta-Puglia, A., Ram, H. H., and Yorinori, J. T. 1997. Soybean disease loss estimates for the top 10 soybean production countries in 1994. Plant Dis. 81:107-110.

56. Yang, X. B., Lundeen, P., and Uphoff, M. D. 1999. Soybean varietal response and yield loss caused by Sclerotinia sclerotiorum. Plant Dis. 83:456-461.

57. Yang, X. B., Workneh, F., and Lundeen, P. 1998. First report of sclerotium production by Sclerotinia sclerotiorum in soil on infected soybean seeds. Plant Dis. 82:264.

58. Yuen, J. E., and Hughes, G. 2002. Bayesian analysis of plant disease prediction. Plant Pathol. 51:404-407. 